\title{
Strategies against multidrug-resistant tuberculosis
}

\author{
R. Loddenkemper, D. Sagebiel, A. Brendel
}

\begin{abstract}
Strategies against multidrug-resistant tuberculosis. R. Loddenkemper, D. Sagebiel, A. Brendel. (C) ERS Journals Ltd 2002.

ABSTRACT: The rise of multidrug-resistant tuberculosis (MDR-TB), defined as tuberculosis showing resistance to at least isoniazid and rifampicin, is a serious threat to tuberculosis control in some high prevalence countries and may have some impact on low prevalence regions as well.

The World Health Organization estimates that 50 million people worldwide are infected with MDR-TB, and that, in the year 2000, 273,000 (3.1\%) MDR-TB cases were among the 8.7 million new tuberculosis cases. In 1998, the highest MDR-TB rates among new cases and the highest combined (new and previously treated cases) MDRTB rates were found in Estonia $(14.1$ and $18.1 \%)$, Henan province in China (10.8 and $15.1 \%)$, Latvia $(9.0$ and $12.0 \%)$, and Ivanovo Oblast $(9.0$ and $12.3 \%)$ and Tomsk Oblast (6.5 and 13.7\%) in the Russian Federation. The risk factors for MDR-TB are previous treatment or relapse, originating from "hot spot" areas, a history of imprisonment, homelessness and possibly also human immunodeficiency virus.

The treatment of multidrug-resistant tuberculosis is difficult due to side-effects and a treatment duration of up to $3 \mathrm{yrs}$, which is expensive and often unsuccessful. Therefore, strategies for the treatment and prevention of multidrug-resistant tuberculosis are urgently required. This requires functioning tuberculosis control programmes (directly observed treatment short course), and, in some high prevalence countries, the introduction of second-line drugs on the basis of appropriate susceptibility testing (directly observed treatment short course-Plus). Only the future will show whether this "ticking time bomb" can be defused.

Eur Respir J 2002; 20: Suppl. 36, 66s-77s.
\end{abstract}

German Central Committee against Tuberculosis (DZK), Lungenklinik Heckeshorn, Berlin, Germany.

Correspondence: R. Loddenkemper German Central Committee against Tuberculosis (DZK)

Lungenklinik Heckeshorn

Zum Heckeshorn 33

14109 Berlin

Germany

Fax: 493080022286

E-mail: loddheck@zedat.fu-berlin.de

Keywords: Control programmes

epidemiology

multidrug resistance

outcome

treatment

tuberculosis

Received: March 82002

Accepted after revision: April 82002
Tuberculosis (TB) is still the leading cause of death in the world due to a single infectious agent, and the number of new TB cases is currently increasing at an annual rate of $2 \%$ [1]. Chemotherapy was introduced $>50$ yrs ago and has contributed to the decline of TB in high-income countries. However, an emerging problem is the development of drug resistance. This poses a major threat to TB control, especially in low-income countries, in which $95 \%$ of all TB cases occur, and where there is often also a high prevalence of coinfection with human immunodeficiency virus (HIV).

In particular, multidrug-resistant tuberculosis (MDRTB), defined as TB showing resistance to at least isoniazid and rifampicin, has become a major concern, at least in some parts of the world. The World Health Organization (WHO) estimates that 50 million people worldwide are infected with MDR-TB, and that $273,000(3.1 \%)$ of the 8.7 million new TB cases in the year 2000 were caused by MDR-TB.

Isoniazid and rifampicin are the two most potent drugs and the mainstay of anti-TB treatment. The treatment of MDR-TB patients is much more difficult and $\sim 100$ times more expensive than that of fully sensitive patients. The aim of the present article is to give an overview of the causes of resistance development, the present situation regarding MDR-TB and its possible impact on TB control, as well as strategies to solve the problem.

\section{Development of resistance}

\section{Definition of drug resistance}

The development of active TB after infection with resistant strains is defined as "primary resistance". This is important in countries with a high prevalence of drug resistance. In most cases, especially where there is existing resistance to more than one drug, resistance develops due to insufficient treatment leading to selection of spontaneously resistant strains. This is defined as "secondary/acquired resistance". By definition, acquired resistance can only develop in patients that have received $\geqslant 4$ weeks' anti-TB chemotherapy [2]. In cases in which it is not known whether the patient has received prior treatment, the term "initial resistance" has been used by the WHO [3]. It is believed that the rate of initial drug resistance reflects the quality and efficacy of treatment programmes, and that a high rate of initial resistance suggests a poor treatment programme.

As this differentiation implies exact knowledge of the development mechanisms of drug resistance, the WHO nowadays distinguishes between "drug resistance among new cases", defined as "presence of resistant strains of $M$. tuberculosis (Mycobacterium tuberculosis) in a newly diagnosed patient who has never received TB drugs or has received them for less 
than one month of treatment", and "drug resistance among previously treated cases", defined as resistance "found in a patient who has previously received at least one month of TB therapy" [4, 5]. In addition, superinfection with resistant strains during treatment may occur and needs to be taken into account [4]. However, its future role in the epidemiology of $\mathrm{TB}$ is unclear at present.

Considering the extent of drug resistance, three definitions are crucial for the management of patients [3]: "monoresistance" is defined as resistance to one of the five first-line drugs (isoniazid, rifampicin, pyrazinamide, ethambutol and streptomycin), whereas "polyresistance" is resistance of $M$. tuberculosis to two or more of the first-line drugs. "Multidrug resistance" (MDR-TB) is a subgroup of polyresistance, in which there is resistance to at least rifampicin and isoniazid, the two most effective drugs against M. tuberculosis [3].

Resistance rates reflect the quality of therapeutic procedures and their knowledge is therefore of great importance [6]. Inadequate $\mathrm{TB}$ treatment results in treatment failure and development of acquired drug resistance. In general, primary resistance reflects poor treatment in the past, whereas acquired drug resistance indicates current poor treatment $[7,8]$.

\section{Causes of drug resistance}

When streptomycin was discovered in 1943 and introduced as the first antibiotic for the treatment of $\mathrm{TB}$, the majority of those treated improved dramatically. In most cases, this improvement was followed by relapse due to streptomycin-resistant strains, and the importance of drug resistance in the treatment of TB became apparent. It is now known that the use of streptomycin monotherapy led to the emergence of resistant strains. Within each wild-type strain of tubercle bacilli, approximately one in every $1 \times 10^{6}$ organisms is spontaneously resistant to at least one of the known drugs [9-11], and patients with cavitary pulmonary disease may carry $1 \times 10^{6}-1 \times 10^{9}$ tubercle bacilli in a single lesion $[9,12,13]$. Therefore, any patient treated with only one effective drug has a very high chance that drug-resistant bacilli will be selected while the susceptible ones are killed [11].

After the introduction of streptomycin and of $p$-aminosalicylic acid in 1946, isoniazid in 1952, and their combined application, it became clear that effective treatment regimens depended on combined chemotherapy given for a sufficiently long period of time $[11,14]$. Multidrug treatment regimens offered a way to overcome the development of resistance in patients who had not been treated previously, as the rate of spontaneous mutation against two or more drugs is very low. In order to cope with the problems caused by the development of drug resistance, other agents effective against $M$. tuberculosis were searched for and discovered (e.g. pyrazinamide in 1952, cycloserine in 1955, ethambutol in 1961, capreomycin in 1961 and rifampicin in 1966). Owing to the introduction of rifampicin and pyrazinamide into combined chemotherapy, the duration of treatment was reduced significantly from a mean of 18-24 months in the
1970 s to 6 months for fully susceptible strains with relapse rates of $<2 \%$ [15].

Due to inadequate drug prescription by physicians and patient nonadherence to suggested treatment regimens, some patients received monotherapy causing acquired resistance. Transmission of drugresistant $M$. tuberculosis to contacts created new TB cases with primary resistance, finally leading to multidrug resistance. This was not viewed as a major problem until the 1990s, when several outbreaks of multidrug resistance were reported in different regions of the world [16-18]. The spread of (multi-)drugresistant $\mathrm{TB}$ was further increased by insufficient $\mathrm{TB}$ control programmes, a lack of financial resources and inadequate isolation and ventilation measures, as well as delayed recognition of MDR-TB [12, 19]. Adequate combined chemotherapy can prevent the emergence and further spread of drug-resistant tubercle bacilli, but "the potential of introducing drug resistance, resulting from a failure to adhere to treatment principles, will never be overcome, even by the development of new drugs" [11].

Since drug resistance develops rapidly, inadequate treatment or nonadherence to treatment commonly leads to the development of drug-resistant disease with subsequent transmission of drug-resistant strains within the community. This may be the result of several overlapping programmatic factors, including poor medical management of treatment, nonestablishment of recommended regimens, the lack of supervised treatment, limited or interrupted drug supply, use of substandard quality drugs with inferior bioavailability, widespread availability of anti-TB drugs without prescription, and poorly managed and supported national TB control programmes [20-22].

The risk factors for MDR-TB are previous treatment or relapse, originating from "hot spot" areas, a history of imprisonment, homelessness and possibly immunosuppressive diseases such as HIV [23-25] and diabetes mellitus [26].

\section{Virulence}

As resistance arises by mutation at a constant frequency, there are some resistant bacilli, which may be transmitted at least occasionally, in every patient. Whether and how fast drug-resistant strains are likely to spread depends on their reproductive fitness, and a mean rate can only be obtained over decades [1]. After $>20$ yrs of using isoniazid and rifampicin together, the median global rate of MDR-TB is estimated to be $\sim 1 \%$ [27, 28].

In some laboratory experiments, resistant strains were less viable than sensitive ones in vitro, and often (though not always) less virulent in guinea pigs [1, 29, 30]. According to some estimates, the reproductive fitness of MDR-TB seems to be linked to the quality of treatment, suggesting that the best control programmes based on short-course chemotherapy can both prevent and contain MDR-TB [1]. However, other recent reports raise the possibility of the emergence of $M$. tuberculosis strains with a high virulence for humans. If these highly virulent bacilli exist, they 
will spread through the community faster than strains of standard virulence [31].

The results of molecular epidemiological studies also suggest that certain $M$. tuberculosis strains have an enhanced capacity to spread within a community. One of these strains, the Beijing genotype, has been associated with outbreaks in several communities throughout the world. A recent publication describes the rapid dissemination of this genotype on one of the Canary Islands during 1993-1996 [32]. This strain became the most common isolate on the island, even though it was not known there before 1993. The authors suspected a higher level of virulence of the Beijing strain, but a correlation with drug resistance could not be confirmed [32]. In a different setting, PFyfFer et al. [33] found a high rate of infection with Beijing strains $(70.8 \%)$ associated with high rates of MDR-TB $(60.9 \%)$ in prisons in Azerbaijan $(n=65)$. Owing to the limitations of the study in this particular setting, careful interpretation of the results is required. It is not known whether the Beijing strain is more virulent and resistant due to its greater fitness or is spreading because primary TB control has failed and patients have been subjected to years of poor treatment [1]. The most likely explanation is a combination of both.

\section{Epidemiology of drug resistance}

Drug resistance, in particular MDR-TB, is very unevenly distributed around the world. Figure 1 shows the prevalence of MDR-TB among new TB cases in countries surveyed during 1994-1999, whereas figure 2 shows the situation in 2000. According to the WHO, an estimated $70 \%$ of new MDR-TB cases occur in just 10 countries, and thus MDR-TB remains a problem of local rather than global importance. The majority of $\mathrm{TB}$ cases remain treatable (cure rate $>85 \%$ ) under standard short-course chemotherapy using cheap and safe first-line drugs [34]. Drug resistance surveys of 54 countries during 1996-1999 showed the highest resistance rates to any drug were in Estonia $(36.9 \%)$, followed by Henan province in China (35\%), Ivanovo Oblast in the Russian Federation (32.4\%) and Latvia (29.9\%). The highest MDRTB rates among new cases (fig. 3) and the highest combined MDR-TB rates (new/previously treated cases) (fig. 4) have been found in Estonia (14.1 and $18.1 \%)$, Henan province in China (10.8 and $15.1 \%$ ), Latvia (9.0 and 12.0\%), and Ivanovo Oblast (9.0 and $12.3 \%)$ and Tomsk Oblast (6.5 and 13.7\%) in the Russian Federation [5]. The situation may become further complicated by the increase in HIV/TB coinfected patients $[35,36]$.

As already stated, the development of drug resistance is usually the result of medical or public health malpractice. In the late 1980s and early 1990s, the MDR-TB epidemic in New York City, NY, USA, was caused mainly by severe underfinancing and thus understaffing of the TB control services, together with an increase in poverty and homelessness as well as an escalating rate of HIV infection [16, 17, 37].

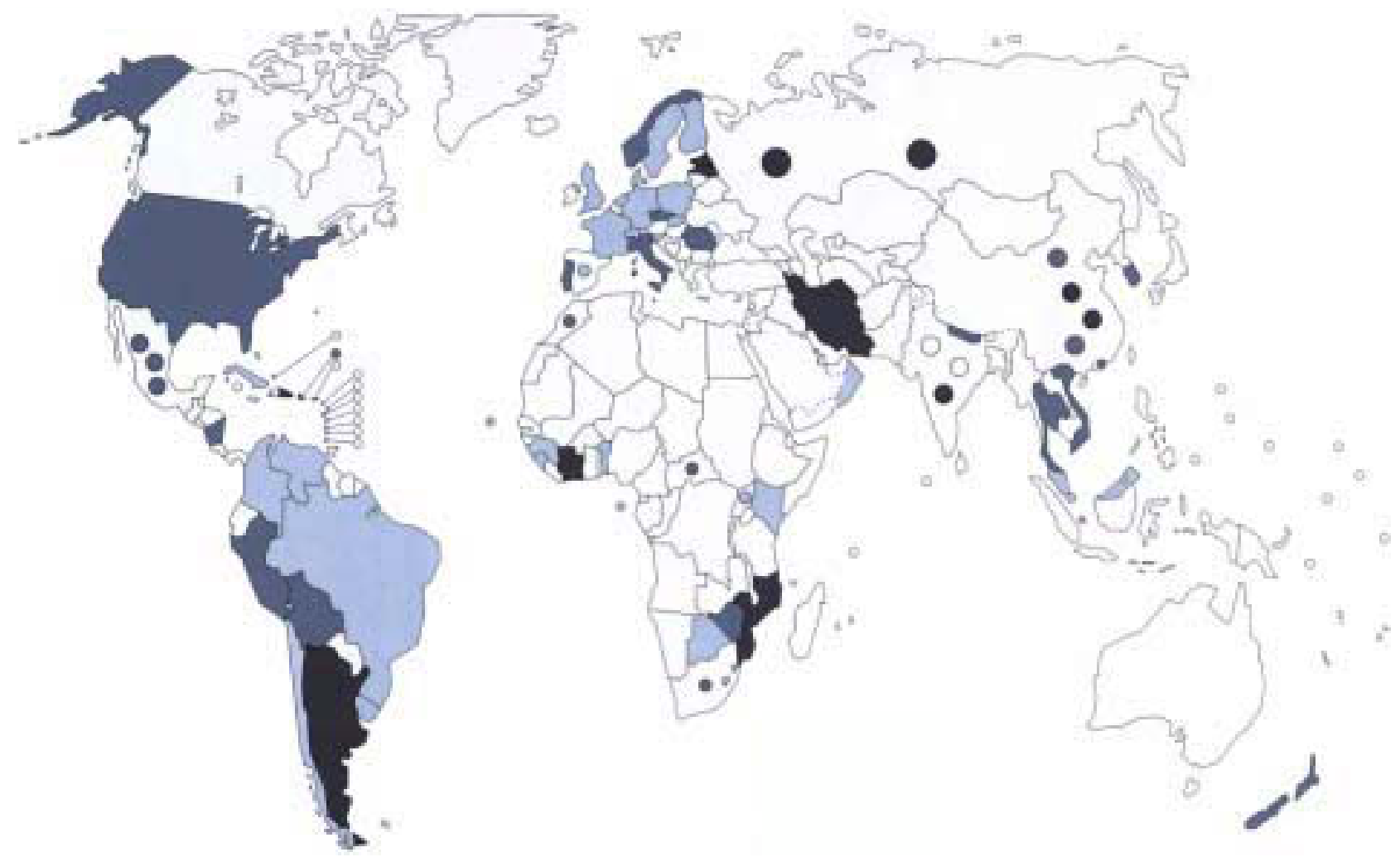

Fig. 1.- Prevalence of multidrug-resistant tuberculosis among new tuberculosis cases in countries and regions surveyed, $1994-1999$. ( 


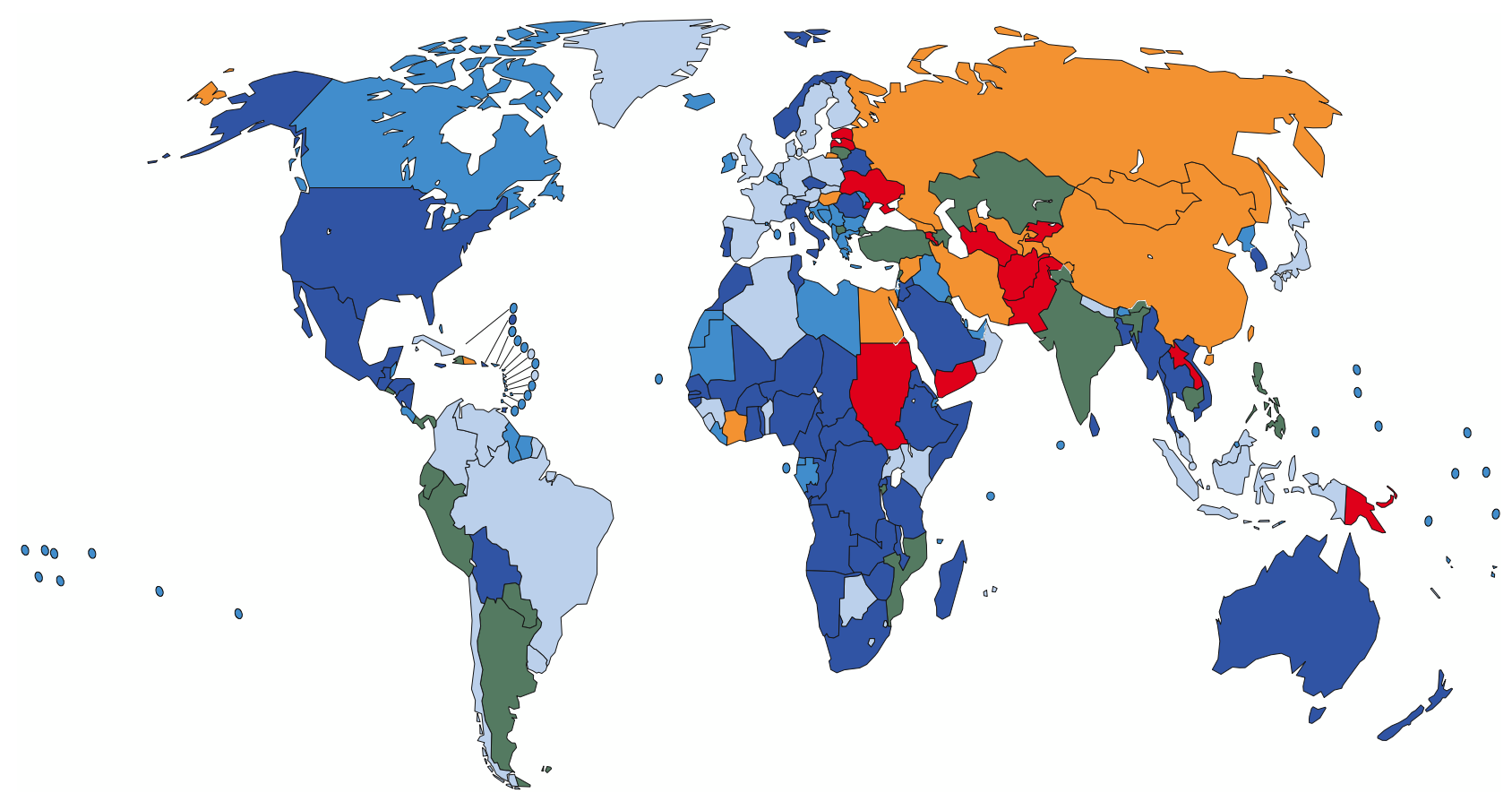

Fig. 2.-Prevalence of multidrug-resistant tuberculosis among new tuberculosis cases in countries and regions surveyed, 2000. : $0-0.9 \%$; $: 1-2.9 \% ; \square: 3-4.9 \%$; : $: 5-6.9 \% ; \square: \geqslant 7 \%$; $:$ : no data

In the newly independent states of the former Soviet Union (NIS), the breakdown of the economy and health services has resulted in an increase in TB. This situation is worsened by the increase in resistant TB (and MDR-TB) due to inadequate TB treatment [35]. The main factors causing this increase in drug resistance are man-made. Inadequate treatment regimens due to prescription malpractice, lack of drug availability and poor quality of anti-TB drugs are major factors and may result in deliberate or unintentional monotherapy. Contributing factors are insufficient patient adherence, malabsorption of the drugs, and programmatic factors such as inadequate patient

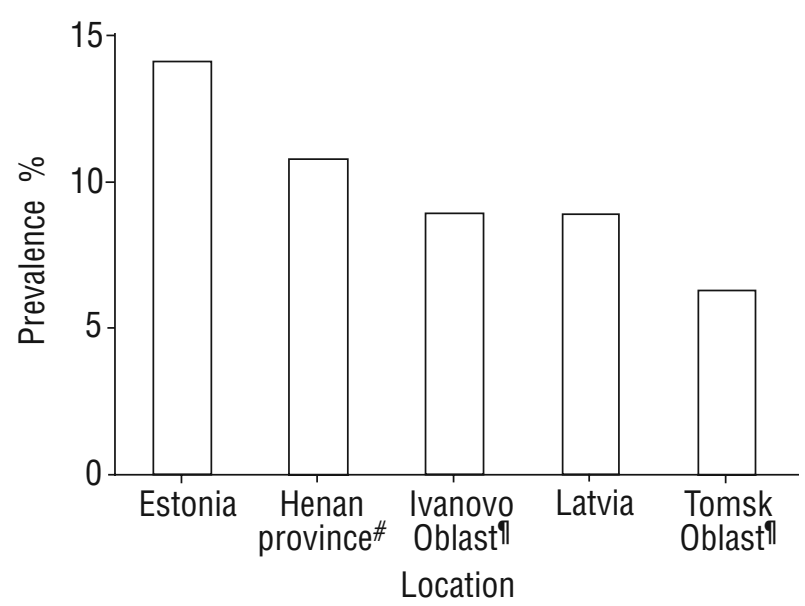

Fig. 3. - Locations with the highest prevalence of multidrug-resistant tuberculosis among new tuberculosis cases ("hot spots").

\#: China; ${ }^{\uparrow}$ : Russian Federation. monitoring and case management, as well as uncontrolled drug distribution. According to Perelman [35], up to $20 \%$ of TB patients in the NIS are already infected with MDR-TB.

As TB does not respect borders, this development influences other industrialised countries, and, for geographical reasons, particularly Western Europe. The present authors' study, including $60 \%$ of all German TB patients, revealed a stable situation and only a slight increase in resistance rates in the year 2000. In Germany, the rate of any resistance in 2000 was $8.7 \%(8.3 \%$ in 1999) and that of MDR-TB 1.7\% $(1.2 \%$ in 1999) (fig. 5). The highest resistance and

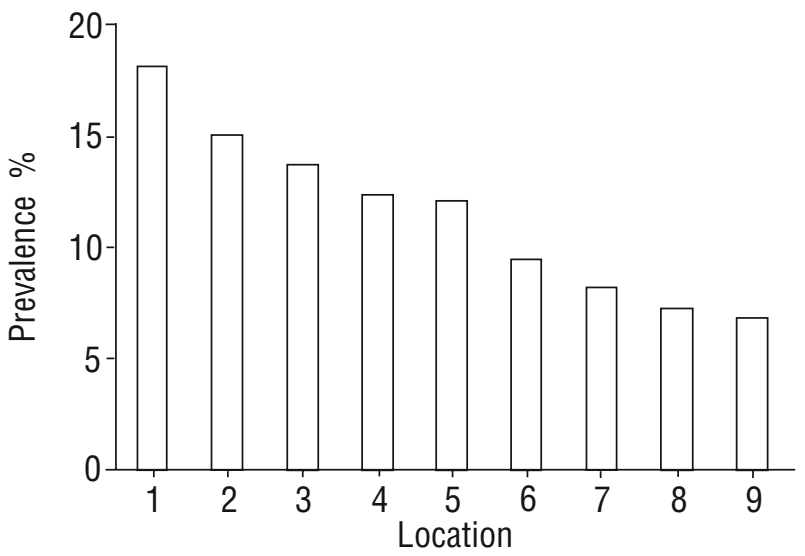

Fig. 4. - Locations with the highest prevalence of combined multidrug-resistant tuberculosis (among both new and previously treated cases). 1: Estonia; 2: Henan province, China; 3: Tomsk Oblast, Russian Federation; 4: Ivanovo Oblast, Russian Federation; 5: Latvia; 6: Zhejiang province, China; 7: Israel; 8: Tamil Nadu state, India; 9: Iran. 


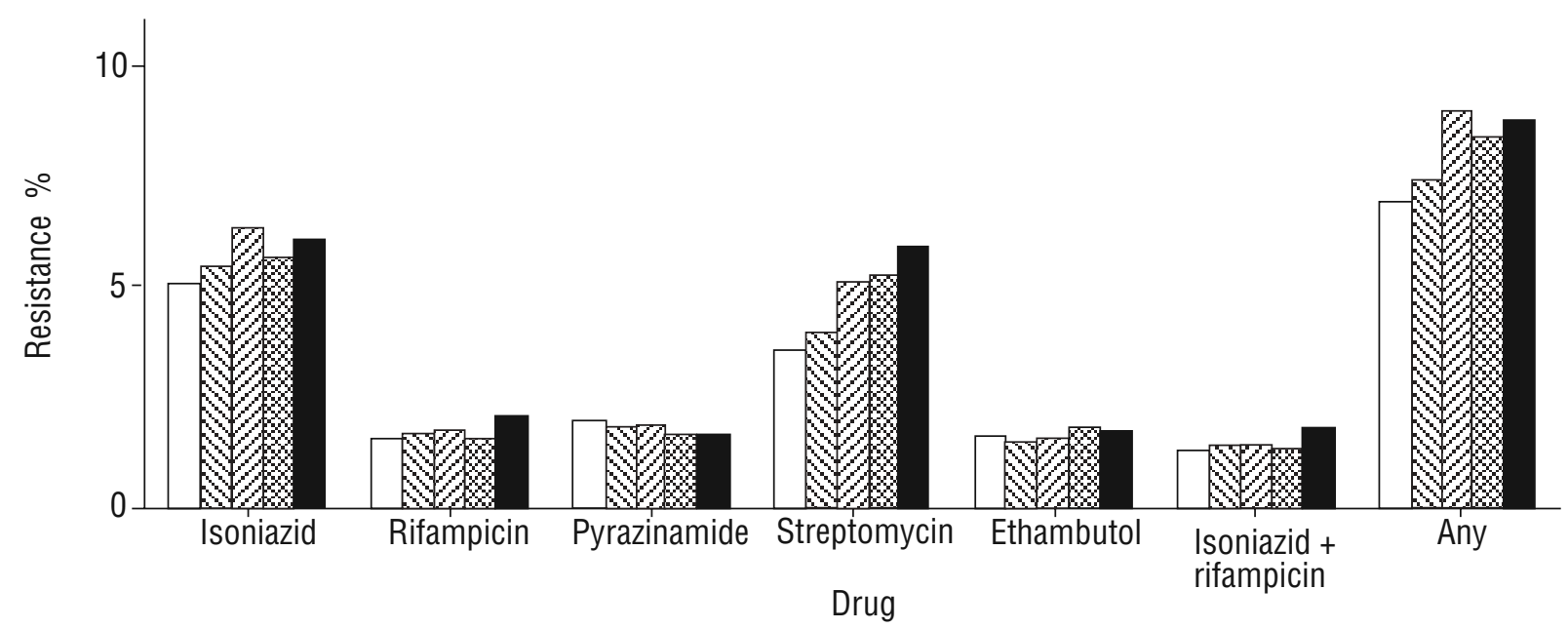

Fig. 5.-Drug resistance among culture-confirmed tuberculosis cases (Mycobacterium tuberculosis complex) in the German Central Committee against Tuberculosis study, 1996-2000. $\square: 1996,2,720 ; \mathbb{\mathbb { N }}: 1997, \mathrm{n}=3,169 ; \mathbb{Z}: 1998, \mathrm{n}=3,273 ; \mathbb{x}: 1999, \mathrm{n}=3,356 ; \mathbf{\square}: 2000$, $\mathrm{n}=2,781$.

MDR-TB rates were found in the foreign-born population, especially those born in the former Soviet Union, with $8.5 \%$ MDR-TB and $33.5 \%$ "any resistance" TB in 2000. These results demonstrate how the worldwide increase in drug resistance may affect other countries, e.g. Germany, in the future. Owing to the dramatic developments in the NIS, there is a high probability of a future increase in drug resistance in Germany, even though no increase was found in patients born in Germany and substantial transmission between these population subgroups has not been detected so far $[38,39]$.

\section{Tuberculosis in prisons}

The complicated situation in prisons and similar institutions requires particular attention, especially in the NIS [40]. In these surroundings, an incidence of up to 7,000 per 100,000 prisoners has been estimated [5]. In the Russian Federation, $\sim 10 \%$ of the 1 million prisoners suffer from TB and the incidence is officially estimated at 3,000 per 100,000 prisoners. According to the study of Portaels et al. [41], the rate of MDR-TB in the prisons of Baku and Mariinsk in the former Soviet Union was $24.6 \%$ (14 of 57) in newly enrolled and $92.1 \%$ (58 of 63) in nonresponding cases [41]. PFYFFER et al. [33] reported an overall rate of MDR-TB of 52.3\% (34 of 65) in a prison in Azerbaijan [33]. In comparison, an MDR-TB rate of $5.9 \%$ was reported for a Spanish prison in 1994 [42], and, during the outbreak in New York City in 1991, 32\% of prisoners were reported to suffer from MDR-TB [43]. It can be postulated that the high resistance rates and increase in HIV, in particular, pose a major threat in these settings.

\section{Human immunodeficiency virus and tuberculosis}

Since the HIV epidemic began 20 yrs ago, $>60$ million people have been infected with HIV. At the end of 2001, an estimated 40 million people globally were living with HIV according to the Joint United Nations Progamme on HIV/acquired immune deficiency syndrome (AIDS). Including the estimated 3.4 million new HIV infections in sub-Saharan Africa, 28.1 million Africans are living with the virus, and 7.1 million people are estimated to be living with HIV/ AIDS in Asia and the Pacific. In 2001, there were an estimated 250,000 new infections in the Eastern European region, bringing the number of people living with HIV to 1 million [44]. Eastern Europe, and particularly the Russian Federation, continues to experience the fastest growing epidemic in the world $[18,34]$. Every year, the number of newly infected people with HIV doubles in the Russian Federation and the total number is estimated to have reached 350,000 [44]. Future effects on the epidemiology of TB are expected to be comparable to the development in the USA in the early 1990s, leading to major problems for the region and the world [45-49].

Owing to a weakened immune defence, people infected with both $M$. tuberculosis and HIV are at greater risk of developing TB. HIV infection is the strongest factor in developing active TB and advanced immunosuppression may also lead to increased reinfection. In many areas with high rates of HIV infection (e.g. sub-Saharan Africa), an annual increase of up to $10 \%$ in TB incidence can be observed [34], and, in some countries, the number of TB cases has doubled due to HIV. Harries et al. [50] report that, in some regions, up to $75 \%$ of $\mathrm{TB}$ patients are HIVpositive. Globally TB is the main single cause of death for HIV patients.

To date, there has been no clear evidence that HIV infection is a risk factor for developing MDR-TB in proper treatment settings [22], but some factors may contribute to an increased risk of MDR-TB in HIV-infected people. Less virulent $M$. tuberculosis strains may appear only in immunosuppressed people and TB due to recent infection with a higher proportion of resistant strains may develop preferentially 
in immunocompromised people [1]. Additionally, there might be shared risk factors between HIV infection and resistant TB (e.g. i.v. drug injection, homelessness and hospitalisation) [1].

\section{Treatment}

Treatment of TB consists of a combination of different antibiotics. The currently recommended standard short-course chemotherapy regime has a duration of 6 months. In the initial (intensive) 2-month phase, four first-line drugs are used (isoniazid, rifampicin, pyrazinamide, and ethambutol or streptomycin), followed, in the 4-month continuation phase, by isoniazid and rifampicin.

Under well-functioning programme conditions of short-course chemotherapy, cure rates of $>90 \%$ can be achieved, implying that only a few patients develop resistance $[1,18,28]$. National programmes that have consistently cured a high proportion of patients for many years regularly report low rates of resistance. Examples of such programmes are those of Chile, China (Beijing), Cuba and Uruguay, achieving cure rates of approximately or $>80 \%$ and reporting mean MDR-TB rates of $<1 \%$ in surveys [1]. Conversely, high rates of resistance tend to be associated with low treatment success. In Ivanovo Oblast, the reported treatment success rate for patients carrying fully sensitive strains was only $75 \%$, and $9 \%$ of new TB cases were reported to be caused by MDR-TB [18, 28].

In patients with drug resistance, the essential principle is to select at least two, preferably three, new drugs to which a recent isolate demonstrates in vitro sensitivity and which the patient has not received before. Second-line drugs should be given on the basis of appropriate drug susceptibility tests, which requires adequate laboratory facilities [51].

Drug susceptibility testing is performed with the purpose of providing crucial information for the treatment of the individual patient, and for the planning of treatment strategies in general. Surveillance of resistance gives a good measure of the efficacy of TB control programmes $[24,52]$. Drug susceptibility testing is urgently needed, particularly in populations with high drug resistance rates. However, the fact that culturebased susceptibility testing requires strict adherence to international quality control standards should also be taken into account $[24,52]$.

After identification of M. tuberculosis, susceptibility testing should be performed with every initial isolate in order to assess drug resistance among new cases and to treat the patient in accordance with these results. If cultures remain positive after 2 months of treatment, susceptibility testing should be repeated to investigate any acquired resistance and to detect possible treatment failures.

The early detection of MDR-TB can improve treatment regimens. As conventional susceptibility testing takes at least 3-4 weeks, there is a significant delay in MDR-TB patients receiving adequate treatment [53]. Faster methods for rapid drug susceptibility testing are not yet widely established, although promising approaches have been developed [53, 54], and are urgently needed in settings with high resistance rates, such as the former Soviet Union. Since rifampicin is the most efficient anti-TB drug, and rifampicin resistance represents an indicator for MDR-TB, rapid susceptibility tests for rifampicin are of great interest. Such tests should be inexpensive and easy to perform without specialised equipment. In a recent study, the FASTPlaqueTB-RIF ${ }^{\mathrm{TM}}$ Rapid test (Biotech Laboratories Ltd, Ipswich, UK) has been shown to have an overall accuracy of $98 \%$ and the results are available after $48 \mathrm{~h}$ from $M$. tuberculosis cultures $[55,56]$.

As the development of MDR-TB is usually associated with poor patient adherence, often accompanied by suboptimal prescription by the physician, directly observed treatment is essential. Treatment regimens for MDR-TB should never be given on an intermittent basis [23]. The treatment of MDR-TB is associated with prolonged illness and disability. The average recommended duration of treatment is $2 \mathrm{yrs}$. The principal second-line drugs are amikacin, capreomycin, cycloserine, ethionamide, flurorquinolones, kanamycin, $p$-aminosalicylic acid and thiacetazone. Second-line anti-TB drugs are generally considered to be less effective than first-line drugs and show a greater frequency of adverse reactions, and are, therefore, less well-tolerated [3, 57], increasing morbidity and cost [58]. Some second-line drugs must be administered more frequently than first-line drugs, making treatment adherence more difficult [58]. In table 1, different treatment options, depending on the underlying resistance patterns, are shown. Nevertheless, it should be mentioned that international guidelines based on randomised studies or evidence-based medicine for the treatment of MDR-TB do not yet exist. The treatment of polyresistant TB is difficult and should be performed only by specialists in experienced centres [58]. In settings with a high prevalence of resistance, or in patients originating from such regions or with assumed drug resistance, it is necessary to strictly isolate patients and to treat them with four or five drugs until the results of drug susceptibility testing are available $[24,59]$. As a principle, a single drug is never added to a failing regimen because of the danger of monotherapy and further induced resistance.

\section{Treatment outcome of multidrug-resistant tuberculosis}

Table 2 summarises the results of four studies which investigated the treatment outcome of patients with MDR-TB who received second-line drugs on the basis of susceptibility testing.

Goble et al. [60] reviewed the clinical courses of 171 patients with pulmonary MDR-TB. For various reasons, 37 were not analysed (22 lost to follow-up, eight deaths, three underwent surgery, three yielded negative cultures before the start of treatment and one received no treatment due to pregnancy). Of the remaining 134 patients with MDR-TB, sputum conversion was reported in 87 cases and 47 remained culture-positive; 63 patients died and 37 of the deaths were attributed to TB. They concluded that, for 
Table 1.- Treatment of drug-resistant tuberculosis: World Health Organization recommendation"

\begin{tabular}{|c|c|c|c|c|}
\hline \multirow[t]{2}{*}{ Drug resistance } & \multicolumn{2}{|r|}{ Initial phase } & \multicolumn{2}{|r|}{ Continuation phase } \\
\hline & Duration months & Drug & Duration months & Drug \\
\hline \multirow{3}{*}{$\begin{array}{l}\mathrm{H}+\mathrm{S} \\
\mathrm{H}+\mathrm{E}+\mathrm{S}\end{array}$} & 3 & $\mathrm{R}, \mathrm{Z}, \mathrm{E}$ & 6 & $\mathrm{R}, \mathrm{E}$ \\
\hline & 2 & $\begin{array}{l}\mathrm{R}, \mathrm{Z} \text {, amikacin, } \mathrm{PTH} \\
\text { Followed by }\end{array}$ & 6 & R, PTH \\
\hline & 1 & $\mathrm{R}, \mathrm{Z}, \mathrm{PTH}$ & & \\
\hline \multirow{4}{*}{$\begin{array}{l}\mathrm{H}+\mathrm{R} \pm \mathrm{S} \\
\mathrm{H}+\mathrm{R}+\mathrm{E}+\mathrm{S} \\
\mathrm{H}+\mathrm{R}+\mathrm{Z}+\mathrm{E}+\mathrm{S}\end{array}$} & $3-6$ & $\begin{array}{l}\mathrm{Z}, \mathrm{E}, \mathrm{PTH} \text {, amikacin, } \\
\text { flurorquinolone }\end{array}$ & 18 & E, PTH, flurorquinolone \\
\hline & & $\mathrm{Z}, \mathrm{PTH}$, amikacin, flurorquinolone, & & \\
\hline & $3-6$ & $\begin{array}{c}\text { cycloserine } \\
\text { PTH, amikacin, flurorquinolone, }\end{array}$ & 18 & PTH, flurorquinolone, cycloserine \\
\hline & $3-6$ & cycloserine, PAS & 18 & PTH, flurorquinolone, cycloserine \\
\hline
\end{tabular}

$\mathrm{H}$ : isoniazid; R: rifampicin; Z: pyrazinamide; E: ethambutol; S: streptomycin; PTH: protionamide/ethionamide; PAS: $p$-aminosalicylic acid. \#: treatment options for known drug resistance. If there is assumed polydrug resistance (treatment failure after standard short-course chemotherapy and directly observed therapy), treat for 3 months with aminoglycoside, protionamide, pyrazinamide and fluoroquinolone followed by 18 months with protionamide and fluoroquinolone. Data taken from [3], [48] and [58].

MDR-TB, even the best available treatment is often unsuccessful.

PARK et al. [61] reviewed the clinical courses of 107 patients with pulmonary MDR-TB. Twenty patients were lost to follow-up, in 22 cases additional surgical resections were performed and two patients interrupted the treatment. Thus, only 63 patients were included and sputum conversion was reported in 52 of these. Including treatment success in surgical patients (21 of 22), 73 of 107 patients could be categorised as "treatment success" (68\%). The authors concluded that MDR-TB responded relatively well to carefully selected regimens.

Another study was reported by van RIE et al. [62] in South Africa. Forty-two patients were included in the study. They observed sputum conversion in 32 patients and treatment success was reported in 25. Treatment failure was reported in five cases and 11 patients died within 5 yrs.

The latest study, by Tahaoglu et al. [63], evaluated the treatment results of 158 patients with MDR-TB. Surgical resections were performed in 36 patients. They reported sputum conversion in 150 patients and treatment success in 121 cases. Success was associated, in particular, with younger age and the absence of previous treatment with ofloxacin. Only 13 patients were categorised as treatment failures. They also stated that most patients with MDR-TB can be cured with the use of appropriate intensive treatment regimens.

In summary, the sputum conversion rate in these studies ranged $51-95 \%$ and the treatment success rate $44-77 \%$ and the reported mortality ranged $0-37 \%$. However, the numbers of patients in each study were small and further study results should be awaited. Furthermore, it should be taken into consideration that the results come mainly from developed countries with good TB control programmes.

These results must be compared to the treatment outcome of short-course chemotherapy with first-line drugs for MDR-TB, assessed by EsPINAL et al. [28] in six countries. Treatment success was reported in $52 \%$ of new MDR-TB patients receiving short-course chemotherapy using 6- or 8-month regimens involving four drugs including isoniazid and rifampicin. It ranged $11-60 \%$ using solely directly observed treatment. A high mortality of $9 \%$ and a high failure rate of $21 \%$ for new cases were reported. Thus, the inclusion of second-line drugs in the treatment of MDRTB was recommended in settings with high rates of MDR-TB and good TB control programmes. DYE et al. [1] concluded from these results that MDR-TB is not absolutely untreatable using short-course chemotherapy.

\section{Indications for surgery}

Surgical interventions were a major treatment approach before the introduction of antibiotics. Today, adjuvant surgery for pulmonary TB is again considered for selected MDR-TB cases if chemotherapy with second-line drugs is not working sufficiently. Major indications for surgical treatment of MDR-TB are persistent cavitations, destruction of one lobe or one lung, failure to convert, previous relapses, and a high or potential risk of relapse, if contraindications to surgery are not present. Bacteriological cure rates of $>90 \%$ have been achieved in experienced centres after surgery and in combination with adequate chemotherapy (table 3) [64-67]. However, in any case, treatment with anti-TB drugs needs to be continued for an appropriate length of time after surgery, usually 18-24 months [23, 67-69]. However, the duration of postoperative drug therapy remains controversial, as does the requirement for second-line drugs in all MDR-TB patients [70].

\section{Immune modulation/immunotherapy/novel approaches}

There are some new adjuvant approaches in the treatment of MDR-TB. These include the concurrent application of immunotherapy with heat-killed M. vaccae. STANFORD et al. [71] examined 337 patients 


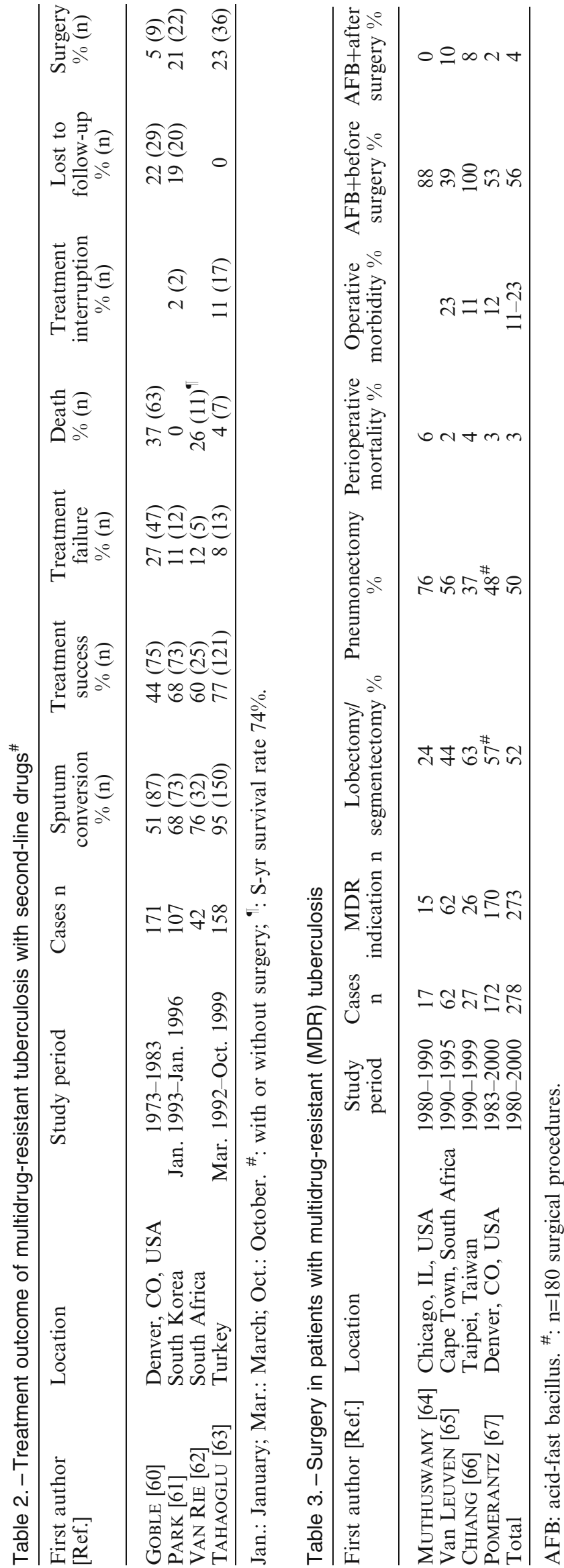

who had received up to 12 doses of $M$. vaccae at 2 -month intervals in addition to chemotherapy. They reported a cure rate of $41.6 \%(n=84)$ and concluded that the additional immunotherapy with $M$. vaccae improves the cure rate of MDR-TB patients, although they stressed the need for a randomised clinical trial.

The use of phenothiazines, which exhibit in vitro activity against MDR-TB with a 10-100-fold higher concentration in $M$. tuberculosis phagocytosing macrophages, is also being examined [72, 73].

Other approaches include cytokine therapy with interleukin-2, interleukin-12, interferon gamma, interferon alpha and granulocyte-macrophage colonystimulating factor [74-76].

However, these approaches are highly controversial and results of further clinical trials are needed before they might be introduced into the treatment of MDRTB.

\section{Strategies}

The spread of antimicrobial resistance is one of the biggest challenges for global public health [77] and successful control of the TB epidemic is of international interest [78]. The impact of the incidence and spread of MDR-TB is affecting both the industrialised and the developing world [5]. TB control strategies are aimed at reduction of transmission through rapid identification of infectious patients and fast adequate diagnostic measures, followed by immediate treatment with effective drugs according to resistance, so long as sufficient protection by vaccination is not available.

An effective fight against $\mathrm{TB}$ requires a strong political foundation and the availability of elementary diagnostic and therapeutic procedures within the framework of internationally recognised standardised treatment regimens, in particular those recommended by the WHO. The basis of preventing and containing the further spread of MDR-TB is, besides poverty reduction, the expansion and application of the directly observed treatment (DOT) short-course (DOTS) strategy with all of its five constituent elements: 1) Political commitment. Successful TB management is impossible without "political commitment" to a functioning national TB programme. For many countries this requires international financial and logistical support; 2) Case finding. In low-income countries, this is achieved primarily through sputum smear microscopy in symptomatic patients. In high-income low-incidence countries, active case finding involves more expensive diagnostic methods [79]; 3) Standardised and supervised short-course chemotherapy (DOTS). In low-income countries, drugs should be administered on an outpatient basis, but under observation, as hospitalisation consumes valuable financial resources; 4) A steady supply of high-quality effective drugs must be secured; 5) A standardised surveillance system including treatment outcome monitoring must be implemented.

Short-course chemotherapy with four drugs (isoniazid, rifampicin, pyrazinamide and ethambutol/ streptomycin in the intensive phase) is only indicated in epidemiological situations with total resistance 
rates of $<10 \%$. In settings with higher resistance rates, five drugs should be given initially [57] and drug susceptibility tests performed, allowing the establishment of extended treatment strategies including second-line drugs [80-82]. Recommended treatment regimens need to be adopted, including five or six drugs for the retreatment of MDR-TB cases [24].

Some of the main obstacles to the management of MDR-TB in resource-limited settings are the absence of epidemiological data about the extent of drug resistance, problems in clinical management, and the high cost of second-line drugs and their rational use, as well as the lack of management of MDR-TB on a national scale [83]. Therefore, enhanced surveillance of TB cases and drug resistance patterns, together with better and faster reporting by medical and laboratory personnel, needs to be established. Efficient monitoring of worldwide drug resistance and the adaptation of successful treatment regimens is required. In regard to this, the $\mathrm{WHO}$ has designed a case-management strategy to manage MDR-TB using second-line drugs within the DOTS strategy (DOTSPlus) in low- and middle-income countries. Certain additional aspects must be considered [51]: 1) the diagnostic prerequisites of microscopic and cultural proof of TB bacteria, as well as drug sensitivity testing, should be applied everywhere; 2) in order to apply treatment strategies efficiently and adequately, it is important to take into account the regional resistance rates of $M$. tuberculosis; 3) direct scientific evaluation of treatment regimens and alternative treatment strategies for polyresistant and MDR-TB cases are necessary to meet regional requirements and control TB effectively; and 4) polyresistant and MDRTB patients should preferably only be treated by specially qualified experts in centres of expertise.

These DOTS-Plus programmes should preferably be implemented in settings with well-functioning and established national TB programmes that promote sound TB control practices for all patients [84]. By fully exploiting the potential of standard short-course chemotherapy based on cheap and safe first-line drugs, it might be possible to hamper the occurrence of future MDR-TB epidemics. By addressing the problem of MDR-TB, the expansion of DOTS might possibly be concurrently promoted and a rational use of second-line drugs may be ensured. The only possible way to avoid future MDR-TB epidemics in some (high-prevalence) regions is through the prevention of the development of further drug resistance [83].

GuPTA et al. [83] described the following possible indications for the introduction of second-line drugs in TB programmes: 1) The emergence of MDR-TB in such high proportions as to be considered a "public health emergency". Specialised teams of experts should rapidly implement adequate TB control programmes, in order to ensure that the implementation of DOTSPlus can follow quickly [18]; 2) The WHO targets are achieved in well-established DOTS-based TB control programmes. Here MDR-TB emerges mainly due to clinical complications and not due to programmatic inadequacies; 3) In countries with inappropriate TB programmes, which are already purchasing and using second-line drugs. The aim is to establish a proper TB control programme in order to prevent the further development of drug resistance [84]; 4) In settings with minimal data available, to prevent a future epidemic. Here the local epidemiology and cost/benefit ratio of introducing DOTS-Plus must be taken into account.

However, the treatment of MDR-TB, with the use of second-line drugs, is far more complex and expensive than that of fully susceptible TB. Therefore, the implementation of an extended, standardised and simple system for the treatment of MDR-TB does not seem feasible. As long as poverty remains one of the main risk factors for the development of $\mathrm{TB}$ and MDR-TB, strategies against MDR-TB will remain ineffective. Through poverty reduction, risk factors such as malnutrition and poor sanitation can be influenced as well as access to healthcare services improved. But TB control programmes alone will never be able to influence the socioeconomic status of whole populations. FARMER et al. [85] conclude that an understanding of what is happening remains far off. They point out the need for new analytical tools and more detailed studies, including the study of the underlying biosocial complexity, in order to extend current understanding.

The successful implementation of DOTS can contribute to a worldwide reduction in TB cases, eventually leading to a decrease of MDR-TB.

Special attention should be focused on risk groups with a history of imprisonment or originating from "hot spot" areas and possibly also HIV-infected people.

The development of new rapid diagnostic tests, effective anti-TB drugs which are easy to use and the development of an efficient vaccine with few sideeffects would constitute an important additional step in the management of TB.

In addition, a close link between the public health level and the medical as well as the research communities is required. At the university and hospital level, better education about TB, MDR-TB and the risks of nosocomial transmission is necessary [24].

\section{Costs}

According to the WHO, TB is estimated to take an annual economic toll equivalent to US\$12 billion from the incomes of poor communities. Studies suggest that, on average, 3-4 months of work time are lost due to $\mathrm{TB}$, resulting in mean lost potential earnings of $20-30 \%$ of the annual household income. For these families, a further income loss of $\sim 15$ yrs due to premature death due to TB is estimated by the WHO [86].

In countries with unstable TB control programmes, treatment regimens should use rifampicin only in the form of combined tablets of proven bioavailability to avoid monotherapy and to control the sale of anti-TB drugs on the private market [87]. The provision of four-first-line-drug fixed-dose combination tablets through the global drug facility for $<\mathrm{US} \$ 10$ per treatment is a promising approach to the treatment of nonresistant TB to prevent the further increase and spread of drug resistance [84].

The treatment of MDR-TB patients is up to 
100 times more expensive than that of fully sensitive patients. The cost effectiveness of DOT for MDR-TB was demonstrated in an assessment between the USA and South Africa. Cost savings of US\$1,788 and US\$2,215 per patient treated with DOT compared to conventional treatment were found. Although conventional treatment was approximately twice the cost of DOT in South Africa (1.5 times with second-line drugs), a saving of $8 \%$ was reported in the USA [88].

White and Moore-GiLlon [89] estimated the overall cost of MDR-TB treatment at 60,000 compared to 6,040 UK pounds for drug-sensitive TB [89].

These studies suggest that DOT represents a costeffective approach, at least in areas of assumed poor compliance.

LAING and McGoldRICK [90] found dramatic variations in drug price between different countries. However, they came to the conclusion that the "free market" seems to be functioning for first-line drugs. For second-line drugs, they pointed out that the "free market" was not functioning efficiently and the true international price was not clear. They reasoned that this was due to the limited number of suppliers and the lack of large-scale tenders. With an increase in DOTS-Plus projects, they expected a decrease in prices.

In order to reduce the immensely high costs and foster the rational use of and access to second-line drugs, the WHO has established a working group for the DOTS-Plus approach [84]. Reduced price secondline drugs should only be given to projects adhering to the international recommendations of a multi-institutional body known as the "Green Light Committee". Thus, countries with budgets that include the purchase of second-line drugs (e.g. Estonia) could save up to $57.5 \%$ of their overall budget for TB control [84].

\section{Conclusion}

The development of drug resistance is usually, but not exclusively, the result of medical or public health deficiencies. In poorly functioning TB control programmes, which result in an increasing number of TB patients and treatment failure, resistance is often caused by inadequate treatment regimens, insufficient patient adherence, and uncontrolled distribution and trade of drugs, as well as lack of availability and poor quality of anti-TB drugs.

Multidrug-resistant tuberculosis is increasing, at least in some regions of the world, and may pose a serious threat globally. Individual approaches to the treatment of multidrug-resistant tuberculosis are difficult, expensive and often unsuccessful. Major efforts are necessary to combat the further rise and spread of multidrug-resistant tuberculosis. The implementation of directly observed treatment short course-Plus as a strategy, which comprises treatment with second-line drugs on the basis of drug susceptibility testing, requires appropriate and functioning tuberculosis control programmes.

\section{References}

1. Dye C, Williams BG, Espinal MA, Raviglione MC. Erasing the world's slow stain: strategies to beat drugresistant tuberculosis. Science 2002 (in press).

2. Pablos-Méndez A, Lazlo A, Bustreo F, . Antituberculosis drug resistance in the world. Publication No. WHO/GTP/97.229. Geneva, World Health Organization Global Tuberculosis Programme, 1997.

3. Crofton J, Chaulet P, Maher D. Guidelines for the management of drug-resistant tuberculosis. Publication No. WHO/TB96.210 (Rev.1). Geneva, World Health Organization, 1997.

4. van Rie A, Gie RP, Enarson D, Beyers N. Classification of drug-resistant tuberculosis in an epidemic area. Lancet 2000; 356: 22-25.

5. World Health Organization/International Union against Tuberculosis and Lung Disease. Antituberculosis drug resistance in the world. Report No. 2. Prevalence and trends (2000). Publication No. WHO/ CDS/TB/2000.278. Geneva, Communicable Diseases, World Health Organization, 1994.

6. Loddenkemper R. The need for antituberculosis drug resistance surveillance in Europe. Eur Respir J 2000; 16: 195-196.

7. Lambregts-van Weezenbeek CSB, Veen J. Origin and management of primary and acquired drug-resistant tuberculosis in the Netherlands: the truth behind the rates. Int J Tuberc Lung Dis 1998; 2: 296-302.

8. World Health Organization/International Union against Tuberculosis and Lung Disease. Guidelines for surveillance of drug resistance in tuberculosis (1994). Publication No. WHO/TB/94.178. Geneva, World Health Organization, 1994.

9. Canetti G. The J. Burns Amberson lecture. Present aspects of bacterial resistance in tuberculosis. Am Rev Respir Dis 1965; 92: 687-703.

10. Mitchison DA. Drug resistance in mycobacteria. $\mathrm{Br}$ Med Bull 1984; 40: 84-90.

11. Rieder HL. Drug-resistant tuberculosis: issues in epidemiology and challenges for public health. Tuber Lung Dis 1993; 75: 321-323.

12. Snider DE, Castro DK. The global threat of drugresistant tuberculosis. N Engl J Med 1998; 338: 16891690.

13. Riska E, Jacobs WR, Alland D. Molecular determinants of drug resistance in tuberculosis. Int $J$ Tuberc Lung Dis 2000; 42: S4-S10.

14. Crofton J. Chemotherapy of pulmonary tuberculosis. BMJ 1957; 1: 1610-1614

15. Iseman MD. Tuberculosis therapy: past, present and future. Eur Respir J 2002; 20: Suppl. 36, 87s-94s.

16. Centers for Disease Control and Prevention. Tuberculosis morbidity - United States 1997. MMWR Morb Mortal Wkly Rep 1998; 47: 253-257.

17. Frieden TR, Sterling T, Pablos-Méndez A, Kilburn JO, Cauthen JO, Dooley SW. The emergence of drugresistant tuberculosis in New York City. $N$ Engl J Med 1993; 328: 521-526.

18. Espinal MA, Laszlo A, Simonsen L, et al. Global trends in resistance to antituberculosis drugs. $N$ Engl J Med 2001; 344: 1294-1303.

19. Mitchison DA. How drug resistance emerges as a result of poor compliance during short course chemotherapy for tuberculosis. Int J Tuberc Lung Dis 1998; 2: 10-15.

20. O'Brien RJ, Nunn PP. The need for new drugs against 
tuberculosis. Obstacles, opportunities, and next steps. Am J Respir Crit Care Med 2001; 163: 1055-1058.

21. Lambregts-van Weezenbeek CSB, Veen J. Control of drug-resistant tuberculosis. Tuber Lung Dis 1995; 76: 455-459.

22. Espinal MA, Laserson K, Camacho M, et al. Determinants of drug-resistant tuberculosis: analysis of 11 countries. Int J Tuberc Lung Dis 2001; 10: 887-893.

23. Albino JA, Reichman LB. The treatment of tuberculosis. Respiration 1998; 65: 237-255.

24. Cole ST, Telenti A. Drug resistance in Mycobacterium tuberculosis. Eur Respir J 1995; 8: Suppl. 20, 701s$713 \mathrm{~s}$.

25. Schaberg T, Gloger G, Reichert B, Mauch H, Lode H. Drug-resistant tuberculosis in Berlin, Germany, 1987-1993. Eur Respir J 1995; 8: 278-284.

26. Bashar M, Alcabes P, Rom WN, Condos R. Increased incidence of multidrug-resistant tuberculosis in diabetic patients on the Bellevue Chest Service, 1987 to 1997. Chest 2001; 120: 1514-1519.

27. Pablos-Méndez A, Raviglione MC, Laszlo A, et al. Global surveillance for antituberculosis-drug resistance, 1994-1997. N Engl J Med 1998; 338: 1641-1649.

28. Espinal MA, Kim SJ, Suarez PG, et al. Standard short-course chemotherapy for drug-resistant tuberculosis. JAMA 2000; 283: 2537-2545.

29. Mitchison DA, Wallace JGM, Bhatia AL, Selkon JB, Subbaiah TV, Lancaster MC. A comparison of the virulence in guinea pigs of South Indian and British tubercle bacilli. Tubercle 1960; 41: 1-22.

30. Ordway DJ, Sonnenberg MG, Donahue SA, Belisle JT, Orme IM. Drug-resistant strains of Mycobacterium tuberculosis exhibit a range of virulence for mice. Infect Immun 1995; 63: 741-743.

31. Davies PD, Grange JM. Factors affecting susceptibility and resistance to tuberculosis. Thorax 2001; 56: Suppl. 2, ii23-ii29.

32. Caminero JA, Pena MJ, Campos-Herrero MI, et al. Epidemiological evidence of the spread of a $\mathrm{Myco}$ bacterium tuberculosis strain of the Beijing genotype on Gran Canaria island. Am J Respir Crit Care Med 2001; 164: 1165-1170.

33. Pfyffer GE, Straessle A, van Gorkum $\mathrm{T}$, et al. Multidrug-resistant tuberculosis in prison inmates, Azerbaijan. Emerg Infect Dis 2001; 7: 855-861.

34. WHO Report 2001. Global tuberculosis control. Publication No. WHO/CDS/TB2001.287. Geneva, World Health Organization, 2001.

35. Perelman MI. Tuberculosis in Russia. Int $J$ Tuberc Lung Dis 2000; 4: 1097-1103.

36. Robert Koch-Institut. HIV/AIDS-Bericht II/2000. Epidemiologisches Bulletin (2001) Sonderausgabe 1/ 2001. Berlin, Robert Koch Institute, 2001

37. Frieden TR, Fujiwara PI, Washko RM, Hamburg MA. Tuberculosis in New York City - turning the tide. $N$ Engl J Med 1995; 333: 229-233.

38. Deutsches Zentralkomitee zur Bekämpfung der Tuberkulose. 27. Informationsbericht, Frankfurt am Main, pmi Verlagsgruppe, 2002.

39. Forssbohm M. Studie des DZK zur Epidemiologie der Tuberkulose - Zwischenbericht 2000. In: Deutsches Zentralkomitee zur Bekämpfung der Tuberkulose. 27. Informationsbericht. Frankfurt am Main, pmi Verlagsgruppe, 2002.

40. Coninx R, Maher D, Reyes H, Grzemska M. Tuberculosis in prison in countries with high prevalence. $B M J$ 2000; 320: 440-442.
41. Portaels F, Rigouts L, Bastian I. Addressing multidrug-resistant tuberculosis in penitentiary hospitals and the general population of the former Soviet Union. Int J Tuberc Lung Dis 1999; 3: 582-588.

42. Chaves F, Dronda F, Cave MD, et al. A longitudinal study of transmission of tuberculosis in a large prison population. Am J Respir Crit Care Med 1997; 155: 719-725.

43. Valway SE, Greifinger RB, Papania M, et al. Multidrug resistant tuberculosis in the New York state prison system, 1990-91. J Infect Dis 1994; 170: 151156.

44. Joint United Nations Progamme on HIV/AIDS. AIDS Epidemic Update. www.unaids.org/epidemicup_date/ report_dec01/index.html Date last updated: December 2001. Date last accessed: May 72002.

45. Loddenkemper R, Hauer B, Sagebiel D, Forssbohm M. Tuberkuloseepidemiologie in Deutschland und der Welt mit Schwerpunkt Osteuropa. BundesgesundheitsblGesundheitsforsch-Gesundheitsschutz 1999; 42: 683693.

46. Migliori GB, Raviglione MC. Specific problems in developing areas of the world. Central and Eastern Europe. In: Davies PDO, ed. Clinical Tuberculosis. 2nd Edn. London, Chapman \& Hall Medical, 1998; pp. 643-660.

47. Raviglione MC, Rieder HL, Styblo K, Khomenko Ag, Esteves K, Kochi A. Tuberculosis trends in Eastern Europe and the former USSR. Tuber Lung Dis 1994; 75: 400-416.

48. World Health Organization, Global Tuberculosis Programme. Treatment of tuberculosis: guidelines for national programmes. 2nd Edn. Publication No. WHO/TB/97.220. 1997. Geneva, World Health Organization, 1997.

49. Zalesky R, Abdullajev F, Khechinashvili G, et al. Tuberculosis control in the Caucasus: successes and constraints in DOTS implementation. Int $J$ Tuberc Lung Dis 1999; 3: 394 401.

50. Harries AD, Maher D, Mvula B, Nyangulu D. An audit of HIV testing and HIV serostatus in tuberculosis patients, Blantyre, Malawi. Tuber Lung Dis 1995; 76: 413-417.

51. World Health Organization. Guidelines for Establishing DOTS-Plus Pilot Projects 2000. Publication No. WHO/CDS/TB/2000.279. Geneva, World Health Organization, 2000.

52. World Health Organization. Laboratory Services in Tuberculosis Control 1998. Publication No. WHO/TB/ 98.258. Geneva, World Health Organization, 1998.

53. Roth A, Schaberg T, Mauch H. Molecular diagnosis of tuberculosis: current clinical validity and future perspectives. Eur Respir J 1997; 10: 1877-1891.

54. Heifets LB, Cangelosi GA. Drug susceptibility testing of Mycobacterium tuberculosis: a neglected problem at the turn of the century. Int J Tuberc Lung Dis 1999; 3: 564-581.

55. Albert H, Heydenrych A, Mole R, Trollip A, Blumberg L. Evaluation of FASTPlaqueTB-RIF ${ }^{\mathrm{TM}}$, a rapid, manual test for the determination of rifampicin resistance from Mycobacterium tuberculosis cultures. Int J Tuberc Lung Dis 2001; 5: 906-911.

56. Foulds $\mathrm{J}, \mathrm{O}^{\prime}$ Brien R. New tools for the diagnosis of tuberculosis: the perspective of developing countries. Int J Tuberc Lung Dis 1998; 2: 778-783.

57. Narita M, Alonso P, Lauzardo M, Hollender E, Pitchenik AE, Ashkin D. Treatment experience of 
multidrug-resistant tuberculosis in Florida, 1994-1997. Chest 2001; 120: 343-348.

58. Deutsches Zentralkomitee zur Bekämpfung der Tuberkulose. Richtlinien zur medikamentösen Behandlung der Tuberkulose im Erwachsenen- und Kindesalter. Pneumologie 2001; 55: 494-511.

59. Iseman MD. Treatment of multidrug-resistant tuberculosis. $N$ Engl J Med 1993; 329: 784-791.

60. Goble M, Iseman M, Madsen LA, Waite D, Ackerson L, Horseburgh CR. Treatment of 171 patients with pulmonary tuberculosis resistant to isoniazid and rifampin. N Engl J Med 1993; 328: 527-532.

61. Park SK, Kim CT, Song SD. Outcome of chemotherapy in 107 patients with pulmonary tuberculosis resistant to isoniazid and rifampin. Int J Tuberc Lung Dis 1998; 2: 877-884.

62. van Rie A, Gie RP, Enarson D, Beyers N. The outcome of MDR-TB patients in an urban area of South Africa. Int J Tuberc Lung Dis 1999; 3: Suppl. 1, S84-S85.

63. Tahaoglu K, Törün T, Sevim T, et al. The treatment of multidrug resistant tuberculosis in Turkey. $N$ Engl J Med 2001; 345: 170-174.

64. Muthuswamy P, Chechani V, Barker W. Surgical management of pulmonary tuberculosis. Am Rev Respir Dis 1992; 145: Suppl. 4, A816.

65. Van Leuven M, de Groot M, Shean K, von Oppell UO, Willcox PA. Pulmonary resection as an adjunct in the treatment of multiple drug-resistant tuberculosis. Ann Thorac Surg 1997; 63: 1368-1373.

66. Chiang CY, Yu MC, Bai KL, Suo J, Lin TP, Lee YC. Pulmonary resection in the treatment of patients with pulmonary multidrug-resistant tuberculosis in Taiwan. Int J Tuberc Lung Dis 2001; 5: 272-277.

67. Pomerantz BJ, Cleveland JC, Olson HK, Pomerantz M. Pulmonary resection for multi-drug resistant tuberculosis. J Thorac Cardiovasc Surg 2001; 121: 448-453.

68. Mahmoudi A, Iseman MD. Surgical intervention in the treatment of drug resistant tuberculosis: update and extended follow up. Am Rev Respir Dis 1992; 145: A816.

69. Rizzi A, Rocco G, Robustellini M, Rossi G, Della Pona C, Massera F. Results of surgical management of tuberculosis: experience in 206 patients undergoing operation. Ann Thorac Surg 1995; 59: 896-900.

70. Park SK, Lee CM, Heu JP, Song SD. A retrospective study for the outcome of pulmonary resection in 49 patients with multidrug-resistant tuberculosis. Int J Tuberc Lung Dis 2002; 6: 143-149.

71. Stanford JL, Stanford CA, Grange JM, Lan NN, Etemadi A. Does immunotherapy with heat-killed Mycobacterium vaccae offer hope for the treatment of multi-drug resistant pulmonary tuberculosis? Respir Med 2001; 95: 435-436.

72. Bettencourt MV, Bosne-David S, Amaral L. Comparative in-vitro activity of phenothiazines against multi-drug resistant Mycobacterium tuberculosis. Int $J$ Antimicrob Agents 2000; 16: 69-71.

73. Amaral L, Kristiansen JE, Viveiros M, Atouguia J.
Activity of phenothiazines against antibiotic-resistant Mycobacterium tuberculosis: a review supporting further studies that may elucidate the potential use of thioridazine as anti-tuberculosis therapy. J Antimicrob Chemother 2001; 47: 505-511.

74. Kamholz SL. Current trends in multidrug-resistant tuberculosis. www.medscape.com/viewarticle/412928. Date last updated: December 11 2001. Date last accessed: May 72002.

75. Holland SM. Cytokine therapy of mycobacterial infections. Adv Intern Med 2001; 45: 431-452.

76. Kristiansen JE, Amaral L. The potential management of resistant infections with non-antibiotics. J Antimicrob Chemother 1997; 40: 319-327.

77. Smith RD. Antimicrobial resistance: the importance of developing long term policy. Bull WHO 1999; 77: 862.

78. Reichman LB, Hopkins Tanne J. Timebomb. The global epidemic of multi-drug-resistant tuberculosis. New York, McGraw-Hill, 2001.

79. Broekmans JF, Migliori GB, Rieder HL, et al. European framework for effective tuberculosis control and elimination in countries with a low incidence. Eur Respir J 2002; 19: 765-775.

80. Espinal MA, Dye C, Raviglione M, Kochi A. Rational DOTS-Plus for the control of MDR-TB. Int J Tuberc Lung Dis 1999; 3: 561-563.

81. Farmer $\mathrm{P}$, Bayona $\mathrm{J}$, Becerra $\mathrm{M}$, et al. The dilemma of MDR-TB in the global era. Int $J$ Tuberc Lung Dis 1998; 2: 869-876.

82. Farmer P. Managerial successes, clinical failures. Int J Tuberc Lung Dis 1999; 3: 365-367.

83. Gupta R, Raviglione MC, Espinal MA. Should tuberculosis programmes invest in second-line treatments for multidrug-resistant tuberculosis (MDR-TB)? Int J Tuberc Lung Dis 2001; 5: 1078-1079.

84. Gupta R, Kim JY, Espinal MA, et al. Responding to market failures in tuberculosis control. Science 2001; 293: 1049-1051.

85. Farmer P, Bayona J, Becerra M. Multidrug-resistant tuberculosis and the need for biosocial perspectives. Int J Tuberc Lung Dis 2001; 5: 885-886.

86. World Health Organization. Materials for World TB Day 2002. www.stoptb.org/world.tbday/WTBD_2002/ default.asp. Date last updated: November 292001. Date last accessed: May 72002.

87. Enarson DA. MDR TB - a ticking time bomb. India Chest 2001; 2: Suppl., S12-S13.

88. Wilton P, Smith RD, Coast J, Millar M, Karcher A. Directly observed treatment for multidrug-resistant tuberculosis: an economic evaluation in the United States of America and South Africa. Int J Tuberc Lung Dis 2001; 5: 1137-1142.

89. White VL, Moore-Gillon J. Resource implications of patients with multi-drug resistant tuberculosis. Thorax 2000; 55: 962-963.

90. Laing RO, McGoldrick KM. Tuberculosis drug issues: prices, fixed-dose combination products and second-line drugs. Int J Tuberc Lung Dis 2000; 4: S194-S207. 